\title{
Analyzing Dynamic Changes of Laboratory Indexes in Patients with Acute Heart Failure Based on Retrospective Study
}

\author{
Yurong Wang, ${ }^{1,2}$ Lei Fu, ${ }^{1,3}$ Qian Jia, ${ }^{1,2}$ Hao Yu, ${ }^{4}$ Pengjun Zhang, ${ }^{1}$ Chunyan Zhang, \\ Xueliang Huang, ${ }^{1}$ Kunlun $\mathrm{He},{ }^{1,5}$ and Yaping Tian ${ }^{1,2}$ \\ ${ }^{1}$ Core Laboratory of Translational Medicine, Chinese PLA General Hospital, Beijing 100853, China \\ ${ }^{2}$ School of Medicine, Nankai University, Tianjin 300071, China \\ ${ }^{3}$ Department of Medical Engineering, 401 Hospital of Chinese PLA, Qingdao 266071, China \\ ${ }^{4}$ Computer Section of Chinese PLA General Hospital, Beijing 100853, China \\ ${ }^{5}$ Department of Cardiology, Chinese PLA General Hospital, Beijing 100853, China
}

Correspondence should be addressed to Yaping Tian; tianyp61@gmail.com

Received 5 January 2016; Revised 9 March 2016; Accepted 20 March 2016

Academic Editor: Laurent Metzinger

Copyright (C) 2016 Yurong Wang et al. This is an open access article distributed under the Creative Commons Attribution License, which permits unrestricted use, distribution, and reproduction in any medium, provided the original work is properly cited.

\begin{abstract}
Background. Changes of N-terminal probrain natriuretic peptide (NT-proBNP) have been studied whether in the long term or the short term in patients of acute heart failure (AHF); however, changes of NT-proBNP in the first five days and their association with other factors have not been investigated. Aims. To describe the dynamic changes of relevant laboratory indexes in the first five days between different outcomes of AHF patients and their associations. Methods and Results. 284 AHF with dynamic values recorded were analyzed. Changes of NT-proBNP, troponin T, and C-reactive protein were different between patients with different outcomes, with higher values in adverse group than in control group at the same time points $(p<0.05)$. Then, prognostic use and risk stratification of NT-proBNP were assessed by receiver-operating characteristic curve and logistic regression. NT-proBNP levels at day 3 showed the best prognostic power (area under the curve $=0.730,95 \%$ confidence interval (CI): 0.657 to 0.794 ) and was an independent risk factor for adverse outcome (odds ratio, OR: 2.185, 95\% CI: 1.584-3.015). Classified changes of NT-proBNP may be predictive for adverse outcomes in AHF patients. Conclusions. Sequential monitoring of laboratory indexes within the first 5 days may be helpful for management of AHF patients.
\end{abstract}

\section{Background}

Acute heart failure (AHF) is the most common reason of hospitalization in patients aged 65 and older, with mortality rate up to $30-40 \%$ within one year $[1,2]$. Prognosis is poor in hospitalized AHF patients $[3,4]$. Accurate prognostic approach and risk stratification may be useful for management of AHF patients.

Surveillance of brain natriuretic peptide (BNP) and Nterminal- (NT-) proBNP in plasma has been reported to be prognostic, offering powerful risk stratification for monitoring the whole HF stages [5]. Kwan et al. concentrated on the prognostic significance of serial measurements of NTproBNP within first 24 hours at admission and again at discharge for patients with chest pain. The results showed that dynamic surveillance of NT-proBNP in the short term did not improve its prognostic ability [6]. Lindahl et al. investigated the prognostic ability of NT-proBNP changes within six months in 1,216 patients with acute coronary syndromes [7] and found NT-proBNP level was stable from 2 days to 6 months and can be more predictive for two-year mortality. Then, Masson and his colleagues analyzed the predictive power of NT-proBNP changes at 4 months from baseline in 1,742 chronic heart failure (CHF) patients [8]. The results revealed that NT-proBNP measurements and classification into four categories of trends may be a superior approach for risk stratification for CHF patients. Myocardial injury, chronic kidney disease (CKD), and pulmonary infection are shown to be high risk factors for mortality of AHF patients, which were well characterized by troponin T (TNT), 
glomerular filtration rate (GFR), and C-reactive protein (CRP) $[9,10]$. In 2013, a report by Metra et al. focused on the short-term (within 2 weeks) dynamics of markers for cardiac, renal, and hepatic damage and cardiac congestion in AHF patients after taking serelaxin [11]. However, sequential dynamics of NT-proBNP and other indexes during the first 5 days and relation among them have not been studied in AHF patients.

The purpose of this study was to observe the changes of NT-proBNP and other indexes within the first 5 days after AHF between patients with different outcomes and their relation, eventually to find the best prognostic approach for AHF patients.

\section{Materials and Methods}

2.1. Study Design and Data Collection. The present study was performed in Chinese PLA General Hospital, Beijing, China. From November 2008 to March 2015, AHF patients presenting to emergency room or intensive care unit were screened. NT-proBNP and other indexes values within the first 5 days were reviewed. Finally, 284 AHF of 251 patients with at least 3 of 5 time points were enrolled, which means that some patients have been enrolled into the study more than once. Then we recorded the baseline information, including sex, age, basic medical history, and vital signs. All data was retrieved from the electronic medical record system of the hospital. The study complied with the guidelines approved by Chinese PLA General Hospital's Ethics Committee. All subjects involved in this study provided informed consents.

The inclusion criteria were established similar to the previous study by Bian et al. [12]. Patients, aged over 18, were enrolled into the study based on the discharge diagnosis of AHF (International Classification of Diseases, Ninth/Tenth Revision coding) or combination of patients' complaint (dyspnea or orthopnea), physical examination (lung rales or oxygen desaturation), and rescue measures (oxygen, mechanical ventilation, diuretics, and cardiac stimulants) or tracheal intubation. The cases without any of the above were excluded.

Patients recovered at discharge were divided into the control group, while patients with all-cause mortality in hospital were divided into the adverse outcome group.

2.2. Definition. Analytical methods used in hospital laboratory were summarized in Figure 1. Categorization of plasma TNT, CRP, and eGFR changes was performed according to the cutoff values defined on the basic of previous researches and guidelines. In accordance with the universal definition of myocardial infarction, TNT level was defined as elevated when its value exceeded $0.01 \mathrm{ng} / \mathrm{mL}$ (the 99th percentile of the upper reference in healthy individuals) [13]. CRP was defined as elevated at the value of $1.00 \mathrm{mg} / \mathrm{dL}$ and less than $90 \mathrm{~mL} / \mathrm{min}$ was defined as eGFR decline [6, 7]. The eGFR was calculated based on formula MDRD with adjustment for gender [14].

2.3. Statistical Analysis. Statistical analysis was performed using SPSS version 19.0. Continuous variables were presented as the mean \pm standard deviation or median $(25$ th -75 th percentiles) according to normality. For differences comparison between groups, independent $t$-test was used for variables normally distributed. Mann-Whitney $U$ test was applied for variables abnormal distribution. Chi-square test was used for categorical variables. Comparison for changes of NT-proBNP, CRP, TNT, and eGFR over time at the same group was assessed by the Wilcoxon signed rank test (or Friedman test). Differences in levels of NT-proBNP, CRP, TNT, and eGFR at the same time point between different groups were analyzed through the Mann-Whitney $U$ test. Log-transformed NTproBNP, TNT, and CRP were also used.

NT-proBNP changes were analyzed in 3 different ways: absolute change from basic level, relative percentage change from basic level, and tendency changes [8]. Tendency changes were defined as four categories according to a cutoff value which was calculated as NT-proBNP concentration at day 3 with the best prediction accuracy for adverse outcome: low to low (cases with NT-proBNP both below the cutoff value); high to low (cases with NT-proBNP above the value at baseline and below at day 3); low to high (cases with NT-proBNP below the value at baseline and above at day 3); and high to high (cases with NT-proBNP both both above the value).

Receiver-operating characteristic (ROC) curve was applied to assess the prognostic usage of NT-proBNP at different time points. Logistic regression was used to assess the odds ratios of single measurement of NT-proBNP and the four categories of changes for adverse outcomes. The latter one was not adjusted for other demographic or clinical indicators. In the study, two-tailed $p$ value $<0.05$ was defined as statistically significant.

\section{Results}

3.1. Clinical Baseline Characteristics. This study included 143 men and 108 women with 284 AHF recorded in total, meaning that some patients are enrolling into the study more than once. Patient baseline characteristics between different clinical outcomes are shown in Table 1. Patients with adverse outcome had more adverse baseline characteristics, such as older age (median 74 years; Q1-Q3, 61-80 years), higher prevalence of CKD (55.2\%) and stroke (29.2\%), and higher level of NTproBNP, TNT, and CRP in plasma, while in controls, NYHA classes III to IV (80.9\%) and a history of CAD (52.1\%) were more prevalent.

3.2. Dynamic Changes of Laboratory Indexes. Significant differences were observed in baseline of NT-proBNP, TNT, CRP, and eGFR between groups with different outcomes (Table 1). Then we analyzed the dynamic changes of the four indexes. Firstly, in 85 AHF with NT-proBNP measurements at all five time points, dynamics of NT-proBNP had a significant decrease over time in control group $(p=0.031)$ but an observable elevation in adverse outcome group (Figure 2(a), $p=0.003)$. Relatively consistent results were obtained in all AHF with NT-proBNP examinations not less than 3 of 5 time points (Figure 2(b), control: $p=0.008$; adverse: $p=0.018$ ). In control group, NT-proBNP baseline was $7024 \mathrm{pg} / \mathrm{mL}$ (2748-13923 pg/mL) and decreased to $4438 \mathrm{pg} / \mathrm{mL}(1725-$ $9460 \mathrm{pg} / \mathrm{mL}$ ) at day 5; however, in adverse group, NT-proBNP 


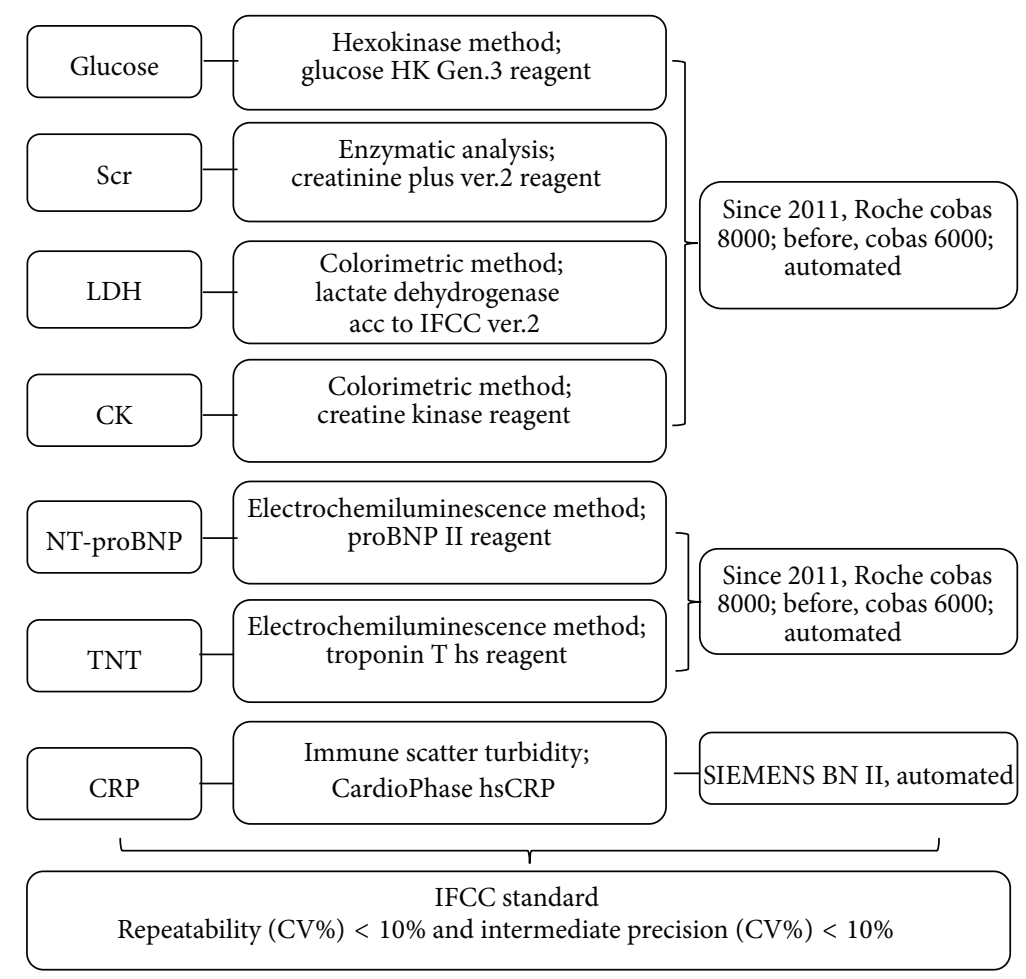

FIGURE 1: Flow chart of analytical methods of all indexes in hospital laboratory.

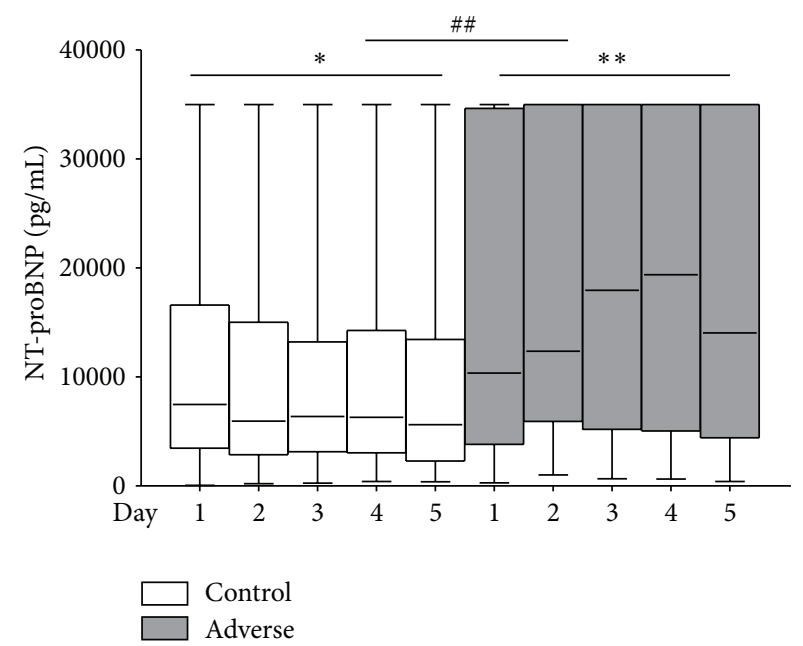

(a)

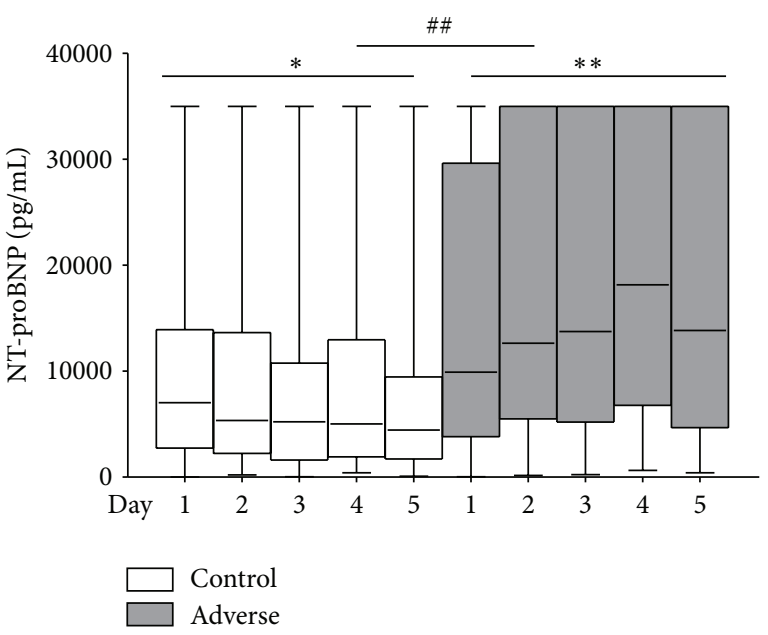

(b)

Figure 2: Plasma NT-proBNP changes over time in AHF patients. (a) showed NT-proBNP levels at days 1 (baseline), 2, 3, 4, and 5 in 85 AHF with measurements at all time points (control, $p=0.031$ and adverse, $p=0.003$ ). (b) NT-proBNP levels over time in all 284 AHF with measurements of 284, 237, 211, 185, and 180 at days $1,2,3,4$, and 5, respectively (control, $p=0.018$, and adverse, $p=0.008$ ). ${ }^{*} p<0.05$, ${ }^{* *} p<0.01$ (significance in the same group); ${ }^{\# \#} p<0.01$ (significance between different groups).

concentration was $9922 \mathrm{pg} / \mathrm{mL}(3825-29632 \mathrm{pg} / \mathrm{mL})$ at baseline and increased to $13855 \mathrm{pg} / \mathrm{mL}(4670-35000 \mathrm{pg} / \mathrm{mL})$ at day 5 . Then changes of other indexes in all patients with at least 3 time points were described as below.

For TNT, in the first tertile, the baseline in control group was $0.021 \mathrm{ng} / \mathrm{mL} \quad(0.018-0.028 \mathrm{ng} / \mathrm{mL})$ and $0.020 \mathrm{ng} / \mathrm{mL}$ $(0.016-0.026 \mathrm{ng} / \mathrm{mL})$ at day $5(p>0.05)$; however, in adverse group, it was $0.030 \mathrm{ng} / \mathrm{mL}(0.017-0.040 \mathrm{ng} / \mathrm{mL})$ at baseline and increased to $0.046 \mathrm{ng} / \mathrm{mL}(0.030-0.075 \mathrm{ng} / \mathrm{mL})$ at day 5 (Figure $3(\mathrm{a}), p=0.007$ ). Then in the upper two tertiles, TNT median (Q1-Q3) level at baseline was $0.117 \mathrm{ng} / \mathrm{mL}(0.056-0.293 \mathrm{ng} / \mathrm{mL})$ and $0.120 \mathrm{ng} / \mathrm{mL}(0.054-$ $0.442 \mathrm{ng} / \mathrm{mL}$ ) in control group, but in adverse group, TNT baseline was $0.196 \mathrm{ng} / \mathrm{mL}(0.104-0.503 \mathrm{ng} / \mathrm{mL})$ and elevated 
TABLE 1: Comparisons of baseline characteristics between AHF patients with different clinical outcomes.

\begin{tabular}{|c|c|c|c|}
\hline \multicolumn{4}{|c|}{$N=284$} \\
\hline & Control $(n=188)$ & Adverse event $(n=96)$ & $p$ value \\
\hline Age (years), median (Q1-Q3) & $67(52-77)$ & $74(61-80)$ & 0.006 \\
\hline Male, $n(\%)$ & $109(58.0)$ & $55(57.3)$ & 0.912 \\
\hline NYHA III to IV, $n(\%)$ & $152(80.9)$ & $67(69.8)$ & 0.036 \\
\hline \multicolumn{4}{|l|}{ History } \\
\hline $\mathrm{CAD}, n(\%)$ & $98(52.1)$ & $67(35.6)$ & 0.004 \\
\hline MI, $n(\%)$ & $77(41.0)$ & $39(40.6)$ & 0.957 \\
\hline Hypertension, $n(\%)$ & $133(70.7)$ & $68(70.8)$ & 0.988 \\
\hline Diabetes, $n(\%)$ & $72(38.3)$ & $40(41.7)$ & 0.583 \\
\hline Arrhythmia, $n(\%)$ & $64(34.0)$ & $36(37.5)$ & 0.564 \\
\hline COPD, $n(\%)$ & $37(19.7)$ & $20(20.8)$ & 0.819 \\
\hline $\mathrm{CKD}, n(\%)$ & $64(34.0)$ & $53(55.2)$ & 0.001 \\
\hline Stroke, $n(\%)$ & $24(12.8)$ & $28(29.2)$ & 0.001 \\
\hline \multicolumn{4}{|l|}{ Vital signs } \\
\hline RR (bpm), median (Q1-Q3) & $18(18-20)$ & $18(18-21)$ & 0.357 \\
\hline Pulse (bpm), mean \pm SD & $94 \pm 21$ & $95 \pm 23$ & 0.656 \\
\hline $\mathrm{SBP}(\mathrm{mmHg})$, mean $\pm \mathrm{SD}$ & $132 \pm 27$ & $126 \pm 23$ & 0.076 \\
\hline $\mathrm{DBP}(\mathrm{mmHg})$, mean $\pm \mathrm{SD}$ & $78 \pm 17$ & $72 \pm 14$ & 0.005 \\
\hline \multicolumn{4}{|l|}{ Lab indexes } \\
\hline $\operatorname{LVEF}(\%)$, mean \pm SD & $43 \pm 11$ & $47 \pm 13$ & 0.114 \\
\hline NT-proBNP (pg/mL), median (Q1-Q3) & $7024(2729-13923)$ & $9922(3825-29632)$ & 0.017 \\
\hline TNT (ng/mL), median (Q1-Q3) & $0.052(0.026-0.194)$ & $0.104(0.042-0.447)$ & 0.002 \\
\hline CRP (mg/dL), median (Q1-Q3) & $1.69(0.40-5.77)$ & $4.20(1.40-14.00)$ & $<0.001$ \\
\hline eGFR (mL/min), median (Q1-Q3) & $73(32-98)$ & $44(21-80)$ & 0.004 \\
\hline CK (U/L), median (Q1-Q3) & $98.9(53.8-171.1)$ & $87(46.8-169.5)$ & 0.251 \\
\hline LDH (U/L), median (Q1-Q3) & $259.5(209.6-334.2)$ & $286.8(220.1-443.5)$ & 0.077 \\
\hline Glucose (mmol/L), median (Q1-Q3) & $8.88(6.25-12.23)$ & $8.06(6.13-10.54)$ & 0.179 \\
\hline
\end{tabular}

to $0.265 \mathrm{ng} / \mathrm{mL}(0.126-1.058 \mathrm{ng} / \mathrm{mL})$ at day 5 (Figure $3(\mathrm{~b})$, $p=0.005)$. As shown, TNT remained at low level over time in control group but continued to rise in adverse group $(p<$ $0.01)$.

For patients in control group, CRP median (Q1-Q3) level was $1.80 \mathrm{mg} / \mathrm{dL}(0.40-6.80 \mathrm{mg} / \mathrm{dL})$ at admission and increased to $3.90 \mathrm{mg} / \mathrm{dL}(0.88-10.33 \mathrm{mg} / \mathrm{dL})$ at day 3 and then dropped to $2.70 \mathrm{mg} / \mathrm{dL}(1.18-5.83 \mathrm{mg} / \mathrm{dL})$ at day 5 ; however, in adverse group, CRP baseline was $5.35 \mathrm{mg} / \mathrm{dL}(1.73-$ $14.48 \mathrm{mg} / \mathrm{dL})$ and $5.45 \mathrm{mg} / \mathrm{dL}(3.30-10.73 \mathrm{mg} / \mathrm{dL})$ at day 3 and $4.65 \mathrm{mg} / \mathrm{dL}(2.13-8.08 \mathrm{mg} / \mathrm{dL})$ at day 5. So, CRP underwent a process of first rose $(p<0.001)$ and then descended $(p=0.003)$ but kept at high level in adverse group without a significant decrease (Figure 3(c)).

In adverse group, eGFR maintained a lower level than that in control group (Figure 3(d)). Baseline of eGFR was $70 \mathrm{~mL} / \mathrm{min}(27-97 \mathrm{~mL} / \mathrm{min})$ without a significant decrease over time in control group; however, in adverse group, it was $41 \mathrm{~mL} / \mathrm{min}(17-76 \mathrm{~mL} / \mathrm{min})$ at admission and decreased to $29 \mathrm{~mL} / \mathrm{min}(15-62 \mathrm{~mL} / \mathrm{min})$ at day 5 . Besides, median levels of the four indexes were significantly different between different groups at the same time points $(p<0.01)$ except that CRP level at day 3.

3.3. Baseline and Changes of NT-proBNP Related to Other Indexes. Univariate analysis showed that NT-proBNP baseline was related to age, TNT, CRP, and eGFR and not significantly associated with history of CAD and stroke, NYHA functional classification, and DBP (Table 2). TNT and CRP baseline level positively correlated with NT-proBNP levels at any time points (Figure $4(\mathrm{a}), p<0.001$ ). And NT-proBNP concentration was elevated at all time points when baseline eGFR declined below $90 \mathrm{~mL} / \mathrm{min}$ (Figure 4(b)).

3.4. NT-proBNP Changes for Predicting the Adverse Outcome of AHF Patients. Because NT-proBNP changes within the first 3 days were stable and more predictive for adverse outcomes, we compared the predictive power of single measurement of NT-proBNP (at days 1, 2, and 3) versus dynamic changes, indicated as absolute or relative changes. ROC curve was used to evaluate the adverse outcome and AUC (95\% CI) increased over time (at admission, days 2 and 3), 

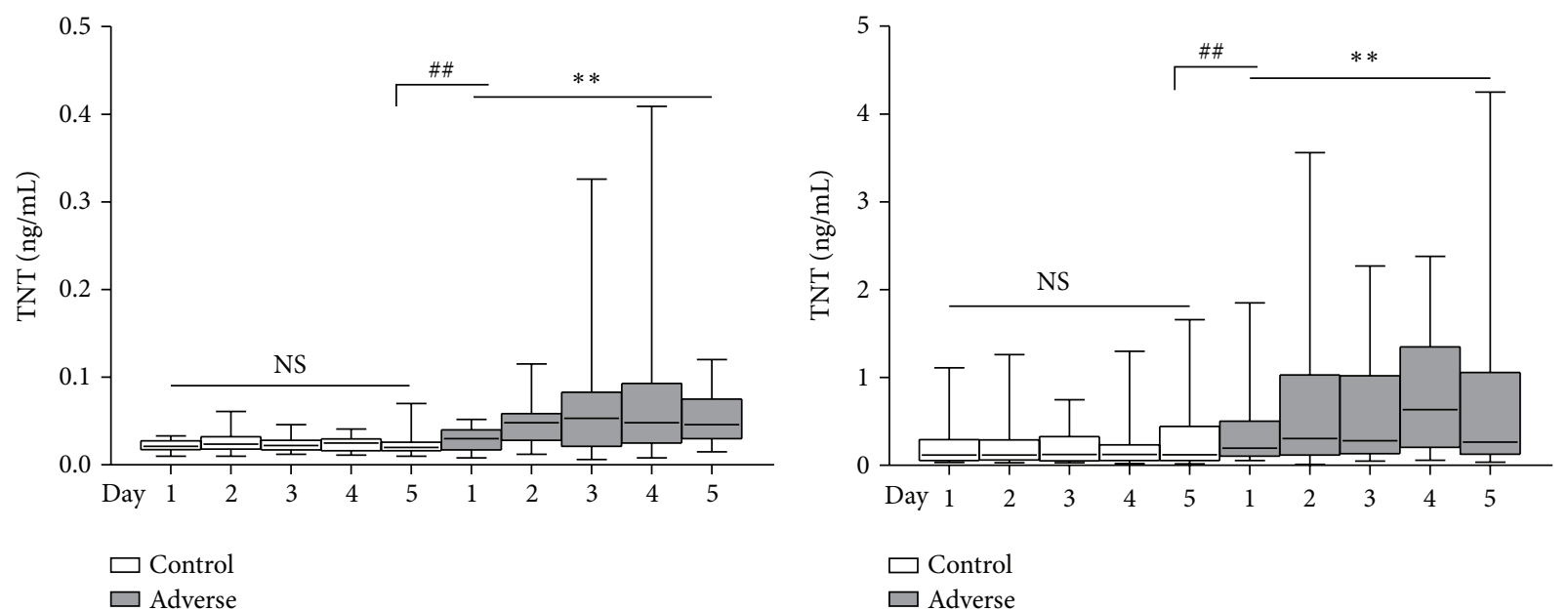

(a)

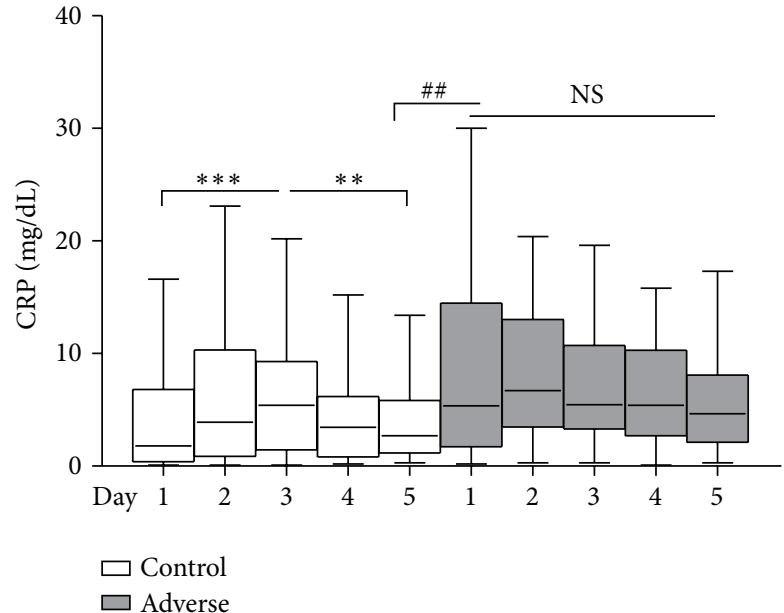

(c)

(b)

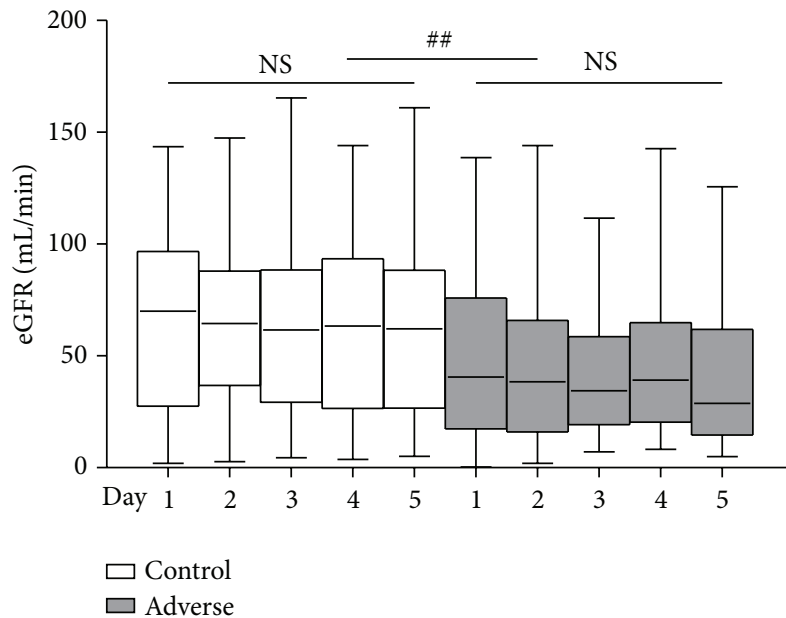

(d)

FIGURE 3: Changes of TNT, CRP, and eGFR over time between AHF patients with different outcomes. TNT changes categorized by percentile at baseline: (a) the first tertile: control, $p>0.05$, and adverse, $p=0.007$; (b) the upper two tertiles: control, $p>0.05$, and adverse, $p=0.005$; (c) changes of CRP over time: control, days 1 to 3, $p<0.001$, days 3 to $5, p=0.003$, and adverse, $p>0.05$; and (d) changes of eGFR over time: control, $p>0.05$, and adverse $p>0.05 .{ }^{* * *} p<0.001,{ }^{* *} p<0.01$ (significance in the same group); ${ }^{\# \#} p<0.01$ (significance between different groups). NS: not significant.

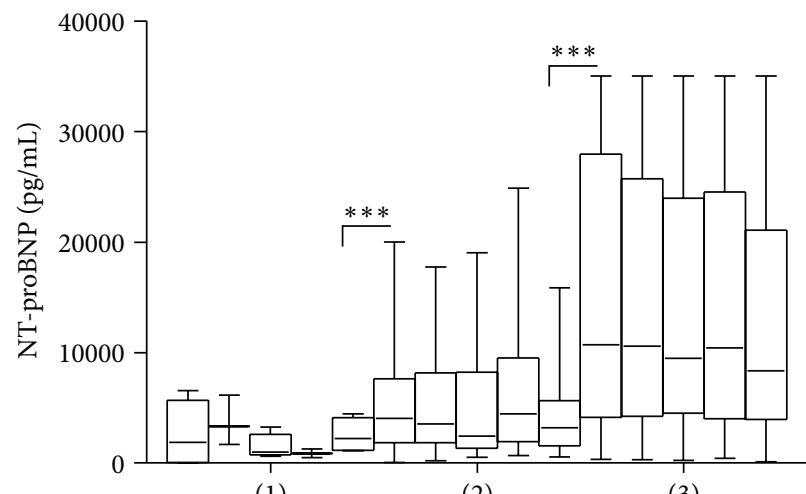

(1)
(2)

(3)

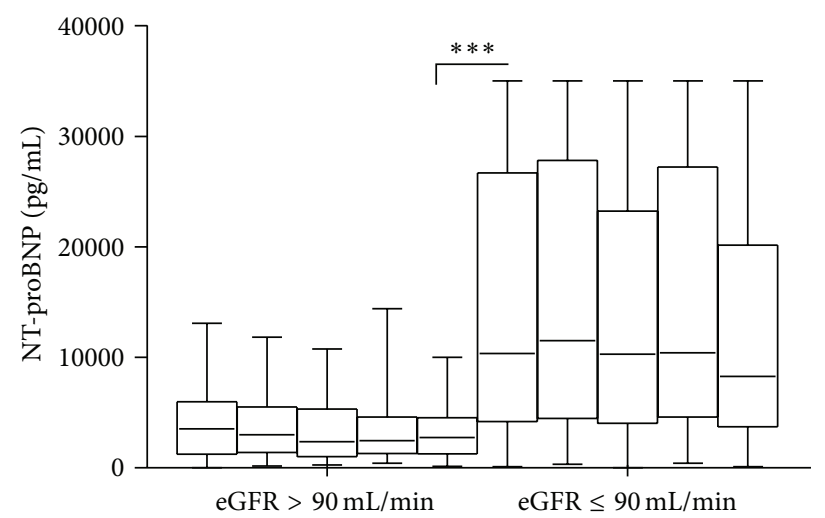

(b)

Figure 4: Changes of NT-proBNP level at admission, days 2, 3, 4, and 5 in patients: (a) (1) without TNT elevation: TNT < $0.01 \mathrm{ng} / \mathrm{mL}$; (2) with TNT elevation, but without elevated CRP: TNT $\geqslant 0.01 \mathrm{ng} / \mathrm{mL}$ and CRP $<1.00 \mathrm{mg} / \mathrm{dL}$; (3) with elevation of both: TNT $\geqslant 0.01 \mathrm{ng} / \mathrm{mL}$ and $\mathrm{CRP} \geqslant 1.00 \mathrm{mg} / \mathrm{dL}$. (b) With eGFR decline and without. ${ }^{* * *} p<0.001$. 
TABLE 2: NT-proBNP baseline related to baseline factors.

\begin{tabular}{|c|c|c|}
\hline & Median pg/mL (Q1-Q3) & $p$ value \\
\hline \multicolumn{3}{|l|}{ Age } \\
\hline$<65$ years & 7994 (3320-19961) & \multirow{4}{*}{0.011} \\
\hline$<75$ years & $10800(4160-28062)$ & \\
\hline$<85$ years & 5319 (2238-10091) & \\
\hline$\geq 85$ years & 7689 (3588-14203) & \\
\hline \multicolumn{3}{|l|}{ NYHA } \\
\hline I to II & 7689 (2323-16930) & \multirow{2}{*}{0.578} \\
\hline III to IV & 7733 (3375-18439) & \\
\hline \multicolumn{3}{|l|}{ CAD } \\
\hline No & 8684 (3889-19139) & \multirow{2}{*}{0.094} \\
\hline Yes & 7253 (2580-13827) & \\
\hline \multicolumn{3}{|l|}{ Stroke } \\
\hline No & $7602(3074-17651)$ & \multirow{2}{*}{0.710} \\
\hline Yes & 8263 (3319-19665) & \\
\hline \multicolumn{3}{|l|}{ DBP } \\
\hline$<78 \mathrm{mmHg}$ & $7295(2932-17520)$ & \multirow{2}{*}{0.164} \\
\hline$\geq 78 \mathrm{mmHg}$ & 7948 (3320-19791) & \\
\hline \multicolumn{3}{|l|}{ TNT } \\
\hline$<0.01 \mathrm{ng} / \mathrm{mL}$ & $1270(31-4474)$ & \multirow{2}{*}{0.003} \\
\hline$\geq 0.01 \mathrm{ng} / \mathrm{mL}$ & 7744 (3214-17818) & \\
\hline \multicolumn{3}{|l|}{ CRP } \\
\hline$<1.00 \mathrm{mg} / \mathrm{dL}$ & 5105 (2007-9551) & \multirow{2}{*}{$<0.001$} \\
\hline$\geq 1.00 \mathrm{mg} / \mathrm{dL}$ & 10437 (3921-27245) & \\
\hline \multicolumn{3}{|l|}{ eGFR } \\
\hline$\geq 90(\mathrm{~mL} / \mathrm{min})$ & 4075 (1505-7492) & \multirow{2}{*}{$<0.001$} \\
\hline$<90(\mathrm{~mL} / \mathrm{min})$ & 10158 (4170-26902) & \\
\hline
\end{tabular}

Abbreviations are the same as shown in Table 1.

TABLE 3: Significant predictors for adverse outcome among AHF patients.

\begin{tabular}{lccc}
\hline & OR & $95 \%$ CI & $p$ value \\
\hline Age $^{*}$ (65 years, +10 years) & 2.032 & $1.147-3.601$ & 0.015 \\
History of CAD & 4.448 & $1.524-12.979$ & 0.006 \\
$\begin{array}{l}\text { Baseline CRP } \\
(1 \text { increment on log scale) }\end{array}$ & 1.856 & $1.420-2.425$ & $<0.001$ \\
$\begin{array}{l}\text { NT-proBNP at day } 3 \\
(1 \text { increment on log scale) }\end{array}$ & 2.905 & $1.583-5.331$ & 0.001 \\
\hline
\end{tabular}

${ }^{*}$ Age: centered at 65 years and 1 increment on 10 -year scale.

which was 0.608 (0.532 to 0.681 ), 0.695 (0.621 to 0.762 ), and 0.730 (0.657 to 0.794$)$, respectively. And the cutoff value of NT-proBNP was $8459 \mathrm{pg} / \mathrm{mL}$ at day 3 . The absolute or relative changes have not improved the prognostic power with 0.680 (0.605 to 0.748$)$ and 0.686 (0.612 to 0.754$)$. In logistic regression model, NT-proBNP concentration at day 3 was an independent predictor for the adverse outcome (OR 2.185, 95\% CI: 1.584-3.015), along with advanced age and history of CAD and CRP (Table 3). Variables associated with the adverse outcome with $p<0.05$ entered as confounding factors in multivariate analysis.
3.5. Classified Changes of NT-proBNP. Adverse outcome rates for AHF patients classified by categorical changes of NTproBNP were presented in Figure 5(a). Adverse outcome rate of patients in high to low group (threshold of $8459 \mathrm{pg} / \mathrm{mL}$ ) was close to those of low to low group (25.0\% versus $25.6 \%$ ) and higher in patients of low to high group than those in group of high to high ( $70.6 \%$ versus $58.2 \%$ ).

Patients with decreased level of NT-proBNP (high to low) had a risk for adverse outcome with OR of 0.967, 95\% CI: $0.238-3.928$, similar to those in the reference group (Figure 5(b)). In contrast, patients with worsened level of NTproBNP had an obviously increased risk of adverse outcome (low to high, OR: 6.960, 95\% CI: 2.181-22.213, $p<0.001$ ), higher than those remaining at high level (high to high, OR: 4.039, 95\% CI: $2.000-8.157, p=0.001$ ). The percentage of patients taking ACEI/ARB and beta-blockers was higher in control group than that in adverse group ( $45.2 \%$ versus $17.9 \%$; $55.9 \%$ versus $38.9 \%$ ). And the proportion of patients taking vasoactive drugs and morphine was lower in control group than that in adverse group (33.5\% versus $61.1 \%$; $13.8 \%$ versus $34.7 \%)$. It suggests that ACEI/ARB and beta-blockers would have protective activity in short-term management of AHF patients (Table 4).

\section{Discussion}

Acute heart failure is characterized by the acute episodes of signs and symptoms because of decompensation of cardiac function, needing emergency treatment. Mortality rate in hospital reaches up to $10 \%$ [15]. NT-proBNP is the wellestablished marker for HF, and its baseline level is predictive for patients with adverse outcomes in short-term [16, 17]. Lindahl and his colleagues found that serial measurements of NT-proBNP could improve its prognostic utility with increasing odds ratio over time [7]. Although the changes in laboratory parameters are important within hours of AHF, it is also necessary to analyze them within the first few days. The purpose of our study is to describe dynamic trends of several main indexes related to outcome of AHF, to warn us to pay close attention on clinical management in the future, and finally to decrease the mortality. In the present study, NTproBNP level at day 3 had the best predictive accuracy within the first 3 days, suggesting that dynamic monitoring NTproBNP is instructive for AHF management. Moreover, classified changes of NT-proBNP at day 3 from baseline would improve the predictive value of its single determination in patients. And this stratification strategy is also used in a different setting of 116 AHF patients, in which NT-proBNP was tested at different time points with intervals from the beginning of treatment to discharge [18]. And their results showed that absolute changes at discharge from baseline had the best predictive power, similar to conclusions from other investigations [19]. Our analysis showed that the usage of stratification strategy in NT-proBNP was more helpful for management of AHF patients.

As shown, higher level of TNT at baseline was associated with higher baseline and elevation of NT-proBNP over time. We know that plasma TNT level is well established for MI [20]. Elevated TNT level may be due to ongoing of the 
TABLE 4: Management of AHF patients between different clinical outcomes.

\begin{tabular}{lccc}
\hline Emergency treatment at admission & Control & Adverse outcome & $p$ value \\
\hline Diuretics, $n(\%)$ & $169(89.9)$ & $87(91.6)$ & 0.649 \\
ACEI/ARB, $n(\%)$ & $85(45.2)$ & $17(17.9)$ & $<0.001$ \\
Beta-blockers, $n(\%)$ & $105(55.9)$ & $58(61.1)$ & 0.007 \\
Vasoactive drugs, $n(\%)$ & $63(33.5)$ & $33(34.7)$ & $<0.001$ \\
Morphine, $n(\%)$ & $26(13.8)$ & $39(41.1)$ & $<0.001$ \\
Digoxin, $n(\%)$ & $78(41.5)$ & $55(57.9)$ & 0.944 \\
Nitrates, $n(\%)$ & $120(63.8)$ & $86(90.5)$ & 0.332 \\
Oxygen supply, $n(\%)$ & $168(89.4)$ & $58(61.1)$ & 0.760 \\
Antiasthmatic, $n(\%)$ & $111(59.0)$ & & 0.745 \\
\hline
\end{tabular}

ACEi: angiotensin-converting enzyme inhibitor; ARB: angiotensin receptor blocker.

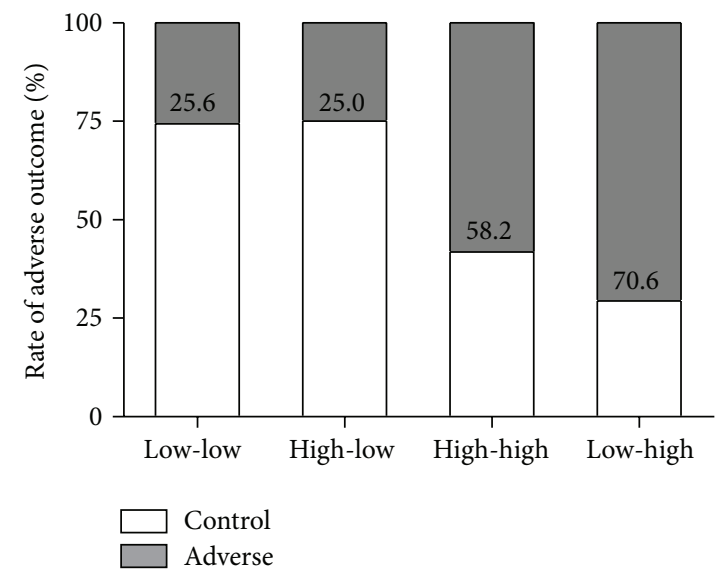

(a)

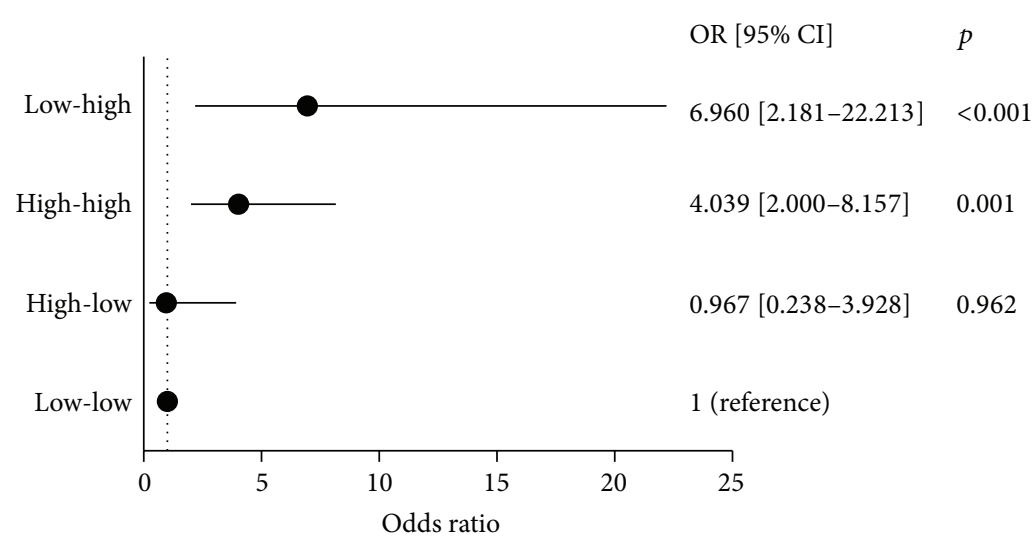

(b)

Figure 5: Classified changes of NT-proBNP. (a) Percentage and (b) odds ratio of classified changes of NT-proBNP for the adverse outcome of AHF patients.

established myocardial necrosis or large infarction area [21, 22]. Both of them could result in the dysfunction of left ventricular and then the subsequent NT-proBNP elevation at baseline. In the present study, TNT remained at low level (baseline median $=0.052 \mathrm{ng} / \mathrm{mL}$ ) in control group; however, it worsened over time (baseline median $=0.104 \mathrm{ng} / \mathrm{mL}$ ) in patients with adverse outcome. In addition, NT-proBNP and TNT sharing the similar trends in adverse group may illustrate the reason above.

More and more researches showed that CRP may be involved in $\mathrm{HF}$ development through activating complement system, stimulating cytokine generation, and then resulting in myocyte loss and functional deterioration [23-25]. Our results showed that CRP in control group rose at first and 
then descended and the level overall was lower than that in adverse group. Moreover, CRP level had an influence on NT-proBNP because elevation of baseline CRP caused elevation of NT-proBNP at baseline and all the time points. Tumor necrosis factor-alpha and interleukin-6 were reported to associate with myocardial dysfunction, then mediating the expression of BNP and NT-proBNP $[26,27]$. CRP can also be upregulated by interleukin- 6 . Therefore, it could explain the association between CRP level and NT-proBNP changes.

The mechanism of ACEIs and ARBs on renin angiotensin system (RAS) is different. ACEI inhibits the angiotensin-converting enzyme and ARBs inhibits Ang II activation through competitively binding to AT1 receptor. Consequently, vascular resistance is reduced, aldosterone is released, and salt and water retention is prevented, causing reduced cardiac preload and afterload. As reported, ARB drugs gave limited endpoints benefits to patients with myocardial infarction and cardiovascular disease, compared with placebo $[28,29]$. However, other investigations showed that ACEI/ARB and betablockers drugs can significantly reduce all-cause mortality and cardiovascular mortality [30-33]. Consistent with them, our results showed that in control group the proportion of patients who received ACEI/ARB drugs and beta-blockers was significantly higher than that in adverse group, further determining their protective roles in management of AHF patients. Morphine use was considered to be associated with increased in-hospital death of AHF patients $[34,35]$. Besides, a review from Ruiz-Laiglesia and Camafort-Babkowski suggested that vasoactive drugs may give benefits in the short term but cause mortality in the long term [36]. Combined with our results, morphine and vasoactive drugs should be used with caution in AHF.

\section{Study Limitations}

This study is a single-center and retrospective control study. Collecting complete continuous data was difficult. Only 85 AHF had complete data sets at all 5 time points, $176 \mathrm{AHF}$ with all first 3 time points, and 284 AHF with at least 3 of 5 time points. Many patients were excluded from this research for without baseline or with only one measurement or died within 24 hours. Second, as a retrospective investigation, we are not sure whether specific treatment influences the outcomes. Finally, sequential monitoring of lab indexes for AHF needs to be assessed and validated in multicenter and large sample prospective research.

\section{Conclusions}

In this single-site study with relative small samples, the prognostic value was better in dynamic assessment of NTproBNP than baseline level. Sequential monitoring of laboratory indexes within the first 3 days of AHF may be helpful for guiding clinical management of AHF patients.

\section{Abbreviations}

ACEi: Angiotensin-converting enzyme inhibitor

AHF: Acute heart failure

$\begin{array}{ll}\text { ARB: } & \text { Angiotensin receptor blocker } \\ \text { CAD: } & \text { Coronary artery disease } \\ \text { CHF: } & \text { Chronic heart failure } \\ \text { CI: } & \text { Confidential interval } \\ \text { CK: } & \text { Creatine kinase } \\ \text { CKD: } & \text { Chronic kidney disease } \\ \text { CK-MB: } & \text { Creatine kinase isoenzyme } \\ \text { COPD: } & \text { Chronic obstructive pulmonary disease } \\ \text { CRP: } & \text { C-Reactive protein } \\ \text { DBP: } & \text { Diastolic blood pressure } \\ \text { eGFR: } & \text { Estimated glomerular filtration rate } \\ \text { LDH: } & \text { Lactic dehydrogenase } \\ \text { LVEF: } & \text { Left ventricular ejection fraction } \\ \text { MI: } & \text { Myocardial infarction } \\ \text { NT-proBNP: N-Terminal probrain natriuretic } \\ & \text { peptide } \\ \text { OR: } & \text { Odds ratio } \\ \text { NYHA: } & \text { New York Heart Association } \\ \text { Q: } & \text { Quartile } \\ \text { ROC: } & \text { Receiver-operating characteristic curve } \\ \text { RR: } & \text { Respiratory rate } \\ \text { SBP: } & \text { Systolic blood pressure } \\ \text { TNT: } & \text { Troponin T. } \\ & \end{array}$

\section{Competing Interests}

The authors declare no conflict of interests related to financial issues or contribution.

\section{Authors' Contributions}

Yaping Tian was chiefly responsible for the investigation. Yaping Tian, Kunlun He, Yurong Wang contributed to the conception and designation of the study. Yurong Wang, Lei $\mathrm{Fu}$, Qian Jia, Hao Yu, and Xueliang Huang collected the data for this analysis. Yurong Wang analyzed the data, prepared figures and tables, and wrote the paper. Pengjun Zhang and Chunyan Zhang helped performing the analysis and carried out constructive discussions. All authors reviewed and approved the final version of this paper.

\section{Acknowledgments}

This investigation was supported by the National High Technology Research and Development Program 863 (no. 2011AA02A111).

\section{References}

[1] S. Laribi, A. Aouba, M. Nikolaou et al., "Trends in death attributed to heart failure over the past two decades in Europe," European Journal of Heart Failure, vol. 14, no. 3, pp. 234-239, 2012.

[2] J. J. McMurray, S. Adamopoulos, S. D. Anker et al., "ESC guidelines for the diagnosis and treatment of acute and chronic heart failure 2012: The Task Force for the Diagnosis and Treatment of Acute and Chronic Heart Failure 2012 of the European Society of Cardiology. Developed in collaboration with the 
Heart Failure Association (HFA) of the ESC,' European Journal of Heart Failure, vol. 14, pp. 803-869, 2012.

[3] P. Jong, E. Vowinckel, P. P. Liu, Y. Gong, and J. V. Tu, "Prognosis and determinants of survival in patients newly hospitalized for heart failure: a population-based study," Archives of Internal Medicine, vol. 162, no. 15, pp. 1689-1694, 2002.

[4] M. R. Cowie, K. F. Fox, D. A. Wood et al., "Hospitalization of patients with heart failure: a population-based study," European Heart Journal, vol. 23, no. 11, pp. 877-885, 2002.

[5] J. L. Januzzi Jr. and R. Troughton, "Are serial BNP measurements useful in heart failure management? Serial natriuretic peptide measurements are useful in heart failure management," Circulation, vol. 127, no. 4, pp. 500-508, 2013.

[6] G. Kwan, S. R. Isakson, J. Beede, P. Clopton, A. S. Maisel, and R. L. Fitzgerald, "Short-term serial sampling of natriuretic peptides in patients presenting with chest pain," Journal of the American College of Cardiology, vol. 49, no. 11, pp. 1186-1192, 2007.

[7] B. Lindahl, J. Lindbäck, T. Jernberg et al., "Serial analyses of Nterminal pro-B-type natriuretic peptide in patients with nonST-segment elevation acute coronary syndromes: a Fragmin and fast Revascularisation during InStability in Coronary artery disease (FRISC)-II substudy," Journal of the American College of Cardiology, vol. 45, no. 4, pp. 533-541, 2005.

[8] S. Masson, R. Latini, I. S. Anand et al., "Prognostic value of changes in N-terminal pro-brain natriuretic peptide in ValHeFT (Valsartan Heart Failure Trial)," Journal of the American College of Cardiology, vol. 52, no. 12, pp. 997-1003, 2008.

[9] M. Gheorghiade and P. S. Pang, "Acute heart failure syndromes," Journal of the American College of Cardiology, vol. 53, no. 7, pp. 557-573, 2009.

[10] M. Metra, G. Cotter, M. Gheorghiade, L. Dei Cas, and A. A. Voors, "The role of the kidney in heart failure," European Heart Journal, vol. 33, no. 17, pp. 2135-2142, 2012.

[11] M. Metra, G. Cotter, B. A. Davison et al., "Effect of serelaxin on cardiac, renal, and hepatic biomarkers in the relaxin in acute heart failure (RELAX-AHF) development program: correlation with outcomes," Journal of the American College of Cardiology, vol. 61, no. 2, pp. 196-206, 2013.

[12] Y. Bian, F. Xu, R.-J. Lv et al., "An early warning scoring system for the prevention of acute heart failure," International Journal of Cardiology, vol. 183, pp. 111-116, 2015.

[13] K. Thygesen, J. S. Alpert, A. S. Jaffe et al., "Third universal definition of myocardial infarction," Circulation, vol. 126, pp. 2020-2035, 2012.

[14] Y.-C. Ma, L. Zuo, J.-H. Chen et al., "Modified glomerular filtration rate estimating equation for Chinese patients with chronic kidney disease," Journal of the American Society of Nephrology, vol. 17, no. 10, pp. 2937-2944, 2006.

[15] A. Link and M. Böhm, "New options in the treatment of acute heart failure," Internist, vol. 55, no. 6, pp. 655-662, 2014.

[16] J. J. Park, D.-J. Choi, C.-H. Yoon et al., “The prognostic value of arterial blood gas analysis in high-risk acute heart failure patients: an analysis of the Korean Heart Failure (KorHF) registry," European Journal of Heart Failure, vol. 17, no. 6, pp. 601-611, 2015.

[17] J. L. Januzzi, R. Van Kimmenade, J. Lainchbury et al., "NTproBNP testing for diagnosis and short-term prognosis in acute destabilized heart failure: an international pooled analysis of 1256 patients: The international collaborative of NT-proBNP study," European Heart Journal, vol. 27, no. 3, pp. 330-337, 2006.
[18] M. Metra, S. Nodari, G. Parrinello et al., "Serial changes and independent prognostic value of NT-proBNP and cardiac troponin-T,' European Journal of Heart Failure, vol. 9, pp. 776786, 2007.

[19] D. Logeart, G. Thabut, P. Jourdain et al., "Predischarge B-type natriuretic peptide assay for identifying patients at high risk of re-admission after decompensated heart failure," Journal of the American College of Cardiology, vol. 43, no. 4, pp. 635-641, 2004.

[20] J. L. Januzzi, G. Filippatos, M. Nieminen, and M. Gheorghiade, "Troponin elevation in patients with heart failure: on behalf of the third universal definition of myocardial infarction global task force: heart failure section," European Heart Journal, vol. 33, no. 18, pp. 2265-2271, 2012.

[21] B. Metzler, A. Hammerer-Lercher, J. Jehle et al., "Plasma cardiac troponin T closely correlates with infarct size in a mouse model of acute myocardial infarction," Clinica Chimica Acta, vol. 325, no. 1-2, pp. 87-90, 2002.

[22] R. D. Kociol, P. S. Pang, M. Gheorghiade, G. C. Fonarow, C. M. O'Connor, and G. M. Felker, "Troponin elevation in heart failure prevalence, mechanisms, and clinical implications," Journal of the American College of Cardiology, vol. 56, no. 14, pp. 1071$1078,2010$.

[23] S. Verma, S.-H. Li, M. V. Badiwala et al., "Endothelin antagonism and interleukin- 6 inhibition attenuate the proatherogenic effects of C-reactive protein," Circulation, vol. 105, no. 16, pp. 1890-1896, 2002.

[24] H. Bahrami, D. A. Bluemke, R. Kronmal et al., "Novel metabolic risk factors for incident heart failure and their relationship with obesity: the MESA (Multi-Ethnic Study of Atherosclerosis) study," Journal of the American College of Cardiology, vol. 51, no. 18, pp. 1775-1783, 2008.

[25] B. Devaux, D. Scholz, A. Hirche, W. P. Klovekorn, and J. Schaper, "Upregulation of cell adhesion molecules and the presence of low grade inflammation in human chronic heart failure," European Heart Journal, vol. 18, no. 3, pp. 470-479, 1997.

[26] R. Jarai, C. Kaun, T. W. Weiss et al., "Human cardiac fibroblasts express B-type natriuretic peptide: fluvastatin ameliorates its up-regulation by interleukin- $1 \alpha$, tumour necrosis factor- $\alpha$ and transforming growth factor- $\beta$," Journal of Cellular and Molecular Medicine, vol. 13, no. 11-12, pp. 4415-4421, 2009.

[27] M. Thielmann, H. Dörge, C. Martin et al., "Myocardial dysfunction with coronary microembolization: signal transduction through a sequence of nitric oxide, tumor necrosis factor- $\alpha$, and sphingosine," Circulation Research, vol. 90, no. 7, pp. 807-813, 2002.

[28] M. H. Strauss and A. S. Hall, "Angiotensin receptor blockers may increase risk of myocardial infarction unraveling the ARB-MI paradox," Circulation, vol. 114, no. 8, pp. 838-854, 2006.

[29] S. Bangalore, S. Kumar, J. Wetterslev, and F. H. Messerli, "Angiotensin receptor blockers and risk of myocardial infarction: meta-analyses and trial sequential analyses of 147020 patients from randomised trials," British Medical Journal, vol. 342, no. 7805, Article ID d2234, 2011.

[30] Y. J. Youn, B.-S. Yoo, J.-W. Lee et al., “Treatment performance measures affect clinical outcomes in patients with acute systolic heart failure: report from the Korean heart failure registry," Circulation Journal, vol. 76, no. 5, pp. 1151-1158, 2012.

[31] N. Polat, A. Yildiz, M. Z. Bilik et al., "The importance of hematologic indices in the risk stratification of patients with acute decompensated systolic heart failure," Turk Kardiyoloji Dernegi Arsivi, vol. 43, no. 2, pp. 157-165, 2015. 
[32] K. W. Prins, J. M. Neill, J. O. Tyler, P. M. Eckman, and S. Duval, "Effects of Beta-blocker withdrawal in acute decompensated heart failure: a systematic review and meta-analysis," JACC Heart Failure, vol. 3, no. 8, pp. 647-653, 2015.

[33] J. Franco, F. Formiga, D. Chivite et al., "New onset heart failure-clinical characteristics and short-term mortality. A RICA (Spanish registry of acute heart failure) study," European Journal of Internal Medicine, vol. 26, no. 5, pp. 357-362, 2015.

[34] Z. Iakobishvili, E. Cohen, M. Garty et al., "Use of intravenous morphine for acute decompensated heart failure in patients with and without acute coronary syndromes," Acute Cardiac Care, vol. 13, no. 2, pp. 76-80, 2011.

[35] P. E. Marik and M. Flemmer, "Narrative review: the management of acute decompensated heart failure," Journal of Intensive Care Medicine, vol. 27, no. 6, pp. 343-353, 2012.

[36] F. J. Ruiz-Laiglesia and M. Camafort-Babkowski, "Vasoactive and inotropic drugs in acute heart failure," Medicina Clinica, vol. 142, supplement 1, pp. 49-54, 2014. 


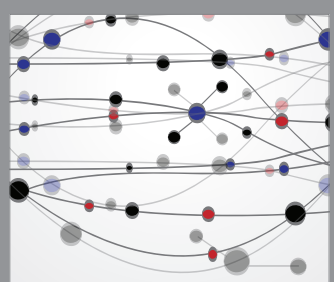

The Scientific World Journal
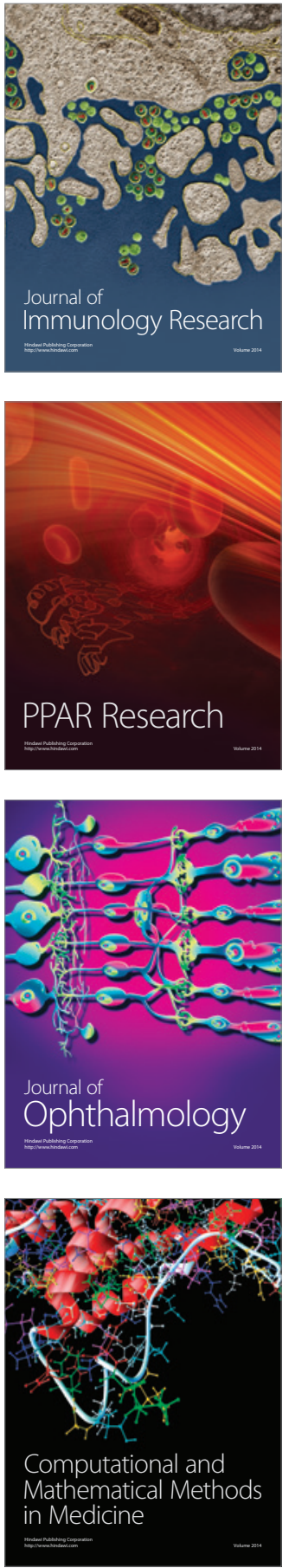

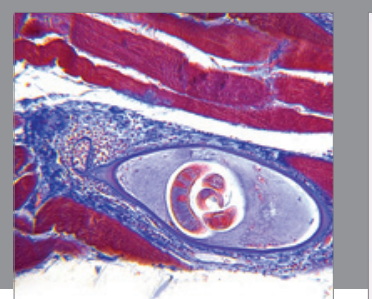

Gastroenterology Research and Practice

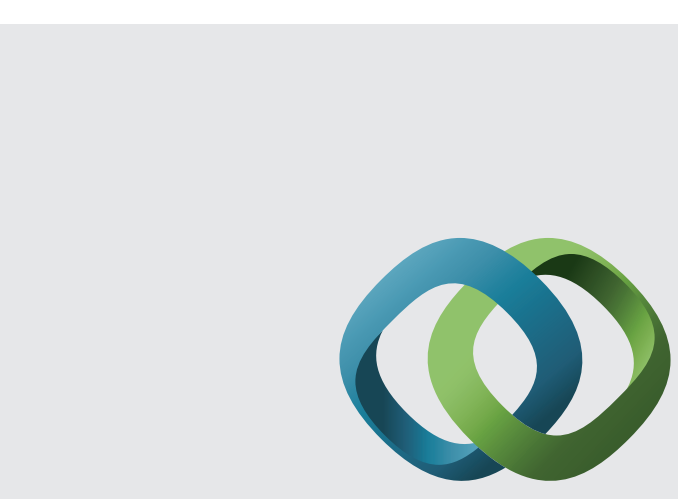

\section{Hindawi}

Submit your manuscripts at

http://www.hindawi.com
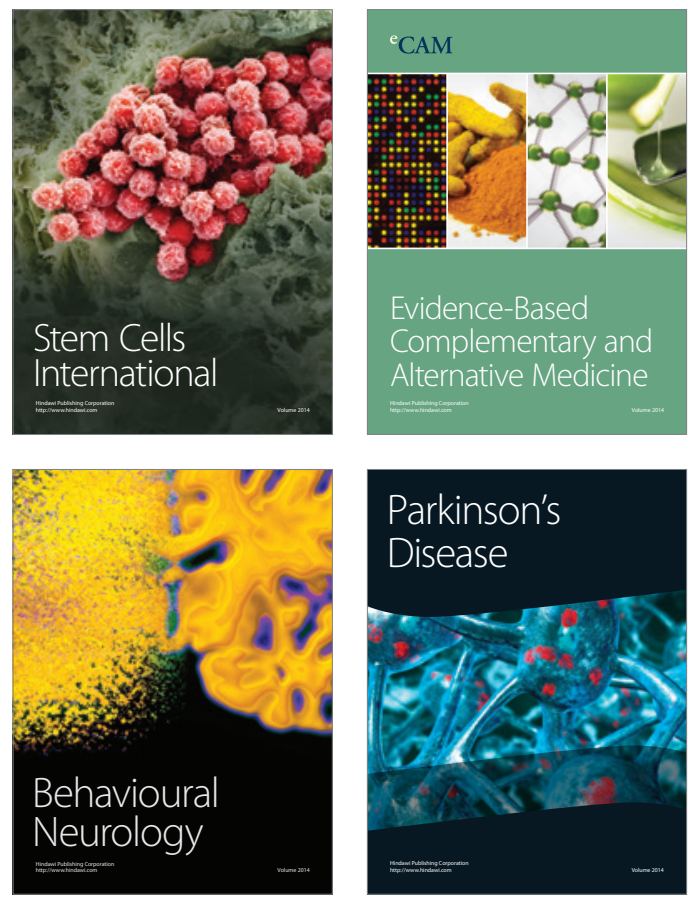
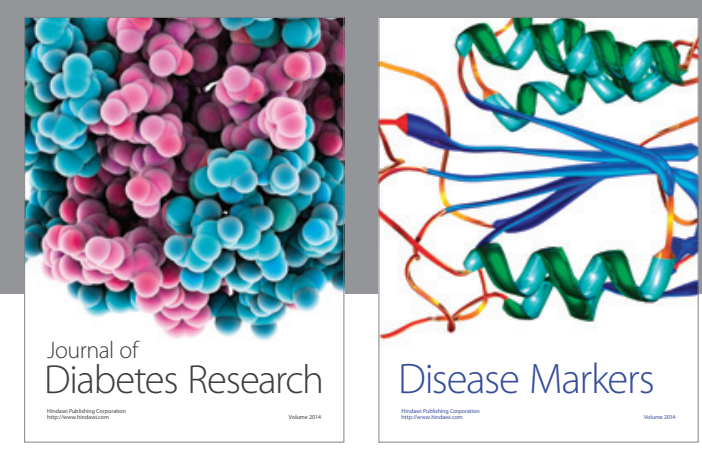

Disease Markers
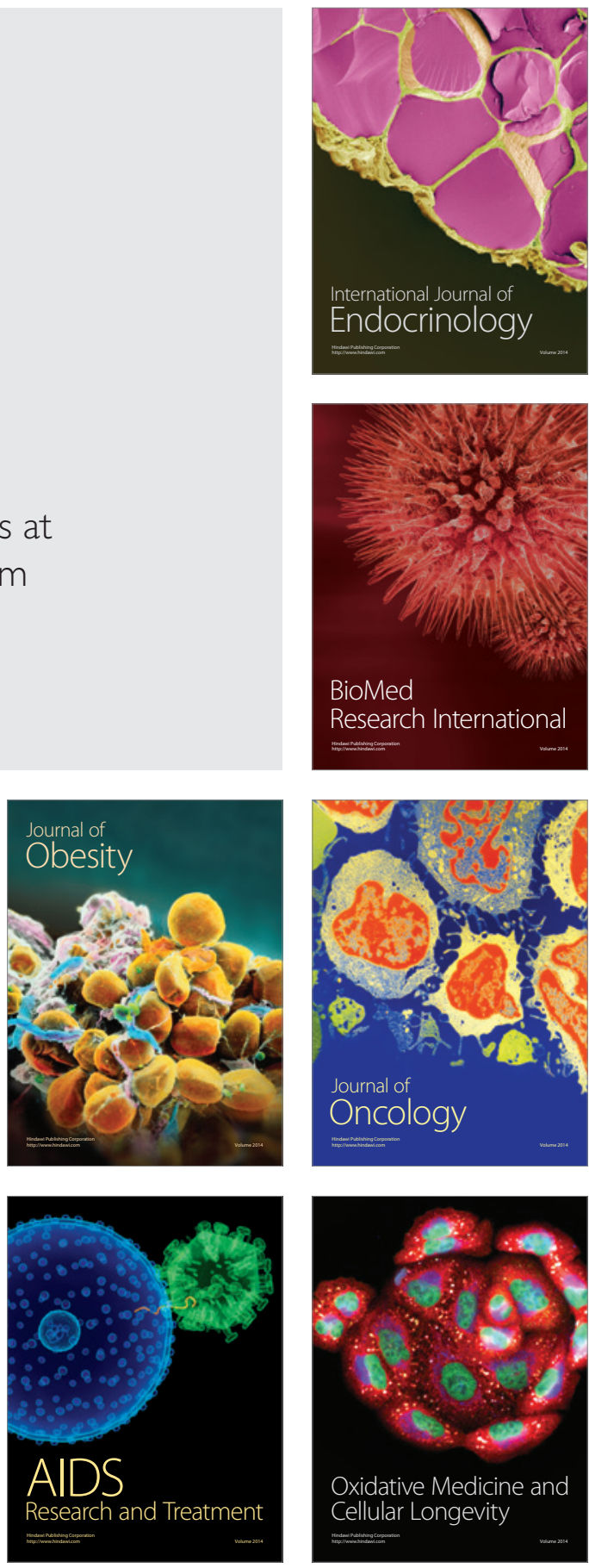